\title{
Variability of residence time in the Tropical Tropopause Layer during Northern Hemisphere winter
}

\author{
K. Krüger ${ }^{1}$, S. Tegtmeier ${ }^{2,1}$, and M. Rex ${ }^{3}$ \\ ${ }^{1}$ Leibniz-Institute for Marine Sciences at Kiel University (IFM-GEOMAR), Kiel, Germany \\ ${ }^{2}$ Environment Canada, Toronto, Canada \\ ${ }^{3}$ Alfred Wegener Institute for Polar and Marine Research, Potsdam, Germany \\ Received: 18 April 2009 - Published in Atmos. Chem. Phys. Discuss.: 28 May 2009 \\ Revised: 13 August 2009 - Accepted: 3 September 2009 - Published: 16 September 2009
}

\begin{abstract}
For the first time the long-term interannual and spatial variability of residence time $(\tau)$ is presented for the TTL between $360 \mathrm{~K}$ and $400 \mathrm{~K}$ potential temperature $(\sim 14$ to $18 \mathrm{~km}$ altitude). The analysis is based on a Lagrangian approach using offline calculated diabatic heating rates as vertical velocities, covering Northern Hemisphere $(\mathrm{NH})$ winters from 1962-2004.

The residence time $\tau_{\mathrm{LCP}-400 \mathrm{~K}}$, being the duration time of air parcels in the layer between the Lagrangian Cold Point (LCP) and $400 \mathrm{~K}$, varies spatially and is longer (>50 days) over the maritime continent as the LCP is lowest there $(<370 \mathrm{~K})$. Comparing three theta layers within the TTL reveals the vertical dependence of $\tau$. We derive a mean duration time of 34 days for 360-380 K (lower TTL), 38 days for $380-400 \mathrm{~K}$ (upper TTL) and 70 days for $360-400 \mathrm{~K}$ theta layers for the 1962-2001 period. A case analysis reveals that $\tau$ is positively skewed for $360-380 \mathrm{~K}$ and $380-400 \mathrm{~K}$ during La Niña and El Niño Southern Oscillation (ENSO) neutral years. For these cases, $\sim 60 \%$ of air parcels travel from $360 \mathrm{~K}$ to $380 \mathrm{~K}$ within 25 days. There is large interannual variability for $\tau$ varying up to $\pm 20 \%$ from the long-term mean, with strongest variability seen in the lower part of the TTL. Statistical analysis reveals a significant anti-correlation between the residence time and the extratropical and subtropical wave driving in the lowermost stratosphere.
\end{abstract}

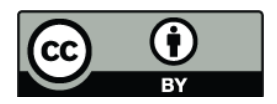

Correspondence to: K. Krüger (kkrueger@ifm-geomar.de)

\section{Introduction}

In recent years the relevance of natural halogenated source gases and primarily the relevance of marine produced very short lived substances (VSLS) has raised up research interests due to their potential for depleting stratospheric ozone, if they reach the stratospheric overworld fast enough (<30 days) (WMO, 2007). The main source region of oceanic VSLS like bromocarbons are located in the tropical oceans especially in upwelling regions close to the coasts (Quack and Wallace, 2003). In the atmosphere, the tropical tropopause layer (TTL) is the main entrance region for trace gases travelling from the troposphere into the stratospheric overworld, where especially the maritime continent during $\mathrm{NH}$ winter season plays a dominant role (Newell and GouldStewart, 1981; Holton and Gettelman et al., 2001; Bonazzola and Haynes, 2004; Fueglistaler et al., 2004). Transport through the TTL primarily arises as large-scale horizontal and slow (weeks to months) vertical processes accompanied by localized rapid (hours) convective overshooting. In this respect the transport time scale of large scale, slow ascent versus meso-scale, rapid overshooting in the TTL, limits the supply of halogens to the stratosphere and hence the stratospheric ozone depletion in mid-latitudes (WMO, 2007). In this study we are particularly interested in the large-scale, slow transport processes in the TTL above $\sim 360 \mathrm{~K}$, which are primarily driven by diabatic radiative heating generated by the eddy driven residual circulation in the stratosphere (Dunkerton, 1978; Haynes et al., 1991). We focus on NH winter, the period of enhanced wave driving, as we aim to investigate the season of shortest residence time in the TTL, which is of relevance for the VSLS supply to the stratosphere.

Published by Copernicus Publications on behalf of the European Geosciences Union. 
Krüger et al. (2008) (hereafter K08) applied a Lagrangian approach to calculate long-term air mass transport through the TTL using offline calculated diabatic heating rates to overcome the known problems of using the noisy and strong vertical velocities of assimilation systems. K08 showed that the geographical distribution of the LCP is very robust and does not seem to be much affected by using the more realistic method with heating rates (alternative approach) compared to the vertical wind method (conventional approach). However, K08 found that differences in the density of LCP trajectories that reach the stratosphere, the distribution of diabatic ascent and in the residence time are all large. For the NH winters 2000-2001 and 2001-2002, they computed an average residence time of $\sim 40$ days between the LCP and $400 \mathrm{~K}$ for the alternative approach and only $\sim 20$ days for the conventional method. Both values lie within the uncertainty range of 20 and 80 days for the $360 \mathrm{~K}$ to $380 \mathrm{~K}$ layer summarized by WMO (2007), which is agreement with recent observational (e.g. Park et al., 2007; Marcy et al., 2007) and Lagrangian estimates (Wohltmann and Rex, 2008; Kremser et al., 2009; Ploeger et al., 2009) for case studies. So far, we are not aware of any other study investigating the longterm interannual and spatial variability of residence time in the TTL.

The current paper will use the method and data described in $\mathrm{K} 08$, presenting the interannual and spatial variability of residence time for the TTL layer between the $360 \mathrm{~K}$ and $400 \mathrm{~K}$ theta levels during NH winter. The questions of how fast, where and when these TTL transport time scales occur will be addressed within this study.

\section{Model and method}

For calculating the inter-annual variability of residence time in the upper part of the TTL during the cold season (NH winter), we are using operational analyses of the European Centre for Medium Range Weather Forecast (opECMWF) (Simmons et al., 2005) and 40 years of ECMWF reanalyses (ERA40) (Uppala et al., 2005). Due to data availability, our Lagrangian analysis has been carried out for the period $1962 / 1963$ to $2004 / 2005$.

In contrast to previous TTL studies, a different approach is used to better constrain the vertical velocities in isentropic trajectory models of this region of the atmosphere: we apply a reverse domain filling trajectory model coupled with a radiative transfer model to calculate diabatic heating rates, that are used as vertical velocities. The model and the method employed are described in detail in K08 and Tegtmeier et al. (2008). The advantage of using diabatic heating rates in the upper part of the TTL is demonstrated for a tropical campaign in the accompanying paper by Immler et al. (2007). The backward trajectories are initialized on a $2^{\circ} \times 2^{\circ}$ grid from $30^{\circ} \mathrm{S}$ to $30^{\circ} \mathrm{N}$ on the $400 \mathrm{~K}$ isentropic level for the period from December to February (DJF). This gives a total number $N$ of 5580 trajectories per period. As we are only interested in the troposphere to stratosphere transport of air masses, the backward trajectories are required to pass the isentropic level of $360 \mathrm{~K}$. To derive the residence time $\tau$ (days) from Lagrangian studies, the duration $(\Delta t)$ the trajectories spend within a given theta layer $(\Delta \Theta$, in $K)$, is sampled. Thus the Lagragian diabatic heating $Q_{L}(\mathrm{~K} /$ day), averaged along the trajectories, is directly related to $\tau$ as it gives the vertical velocity in $\Delta \Theta$ per $\Delta t$. The two quantities are anticorrelated with each other, e.g. a stronger diabatic upwelling leads to a shorter residence time. The residence time is computed along each trajectory as the average between $\mathrm{LCP}$ and $400 \mathrm{~K}\left(\tau_{\mathrm{LCP}-400 \mathrm{~K}}\right), 380 \mathrm{~K}$ and $400 \mathrm{~K}\left(\tau_{380 \mathrm{~K}-400 \mathrm{~K}}\right)$,

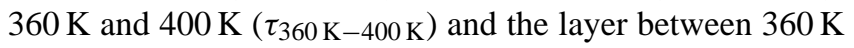

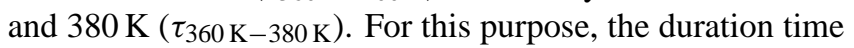
is calculated during the first crossing point of the requested theta layer. The climatology maps of $\tau$ show averages of trajectory portions inside a $5^{\circ} \times 5^{\circ}$ box. Only grid boxes sampled by trajectories are shown. Tropical averages are calculated between $30^{\circ} \mathrm{S}$ and $30^{\circ} \mathrm{N}$. The density $(v)$ of the trajectories is given by $\nu=n /(N n y)$, where $n$ is the number of trajectories sampled inside a grid box and $n y$ is the number of years.

\section{Results}

\subsection{Spatial variability of residence time}

For a better comparison with our companion study (K08), tropical maps of residence time for the TTL layer between LCP and $400 \mathrm{~K}$ are shown for different time periods (Fig. 1). The duration time and the amount of water vapour within air parcels during the TTL passage determine the chemical processes and life time of VSLS reaching the stratosphere. The long-term DJF mean from 1962-2001 displays the maximum residence time of more than 50 days over the maritime continent, due to the fact that the LCP reaches its minimum tropopause height of less than $370 \mathrm{~K}$ over this region. This leads, perhaps unexpectedly, to the longest $\tau$ between LCP and $400 \mathrm{~K}$. A secondary smaller maximum of 50 days is displaced northeast of Brazil, where again the LCP tropopause minimizes at $380 \mathrm{~K}$. On the right side of Fig. 1, the zonal mean $\tilde{\tau}_{\mathrm{LCP}-400 \mathrm{~K}}$ ( $\sim$ stands for zonal mean) is compared with $\tilde{\tau}$ for fixed theta layers. $\tilde{\tau}_{\mathrm{LCP}-400 \mathrm{~K}}$ shows a distinct meridional shape of residence time mirroring the meridional distribution of the LCP tropopause, which has its maximum $\tilde{\tau}_{\mathrm{LCP}-400 \mathrm{~K}}$ (minimum $Q_{\mathrm{LCP}-400 \mathrm{~K}}$, not shown here) over the Equator with decreasing (increasing) values towards the subtropics. For a better quantification of the residence time of air parcels within the TTL, we display $\tilde{\tau}$ for three different theta layers in the TTL (Fig. 1, right side). The shape of $\tilde{\tau}$ for fixed theta layers changes considerably. $\tilde{\tau}_{380 \mathrm{~K}-400 \mathrm{~K}}$ has a minimum of 35 days north of the Equator towards the $\mathrm{NH}$ winter hemisphere and a maximum of 41 days south of 


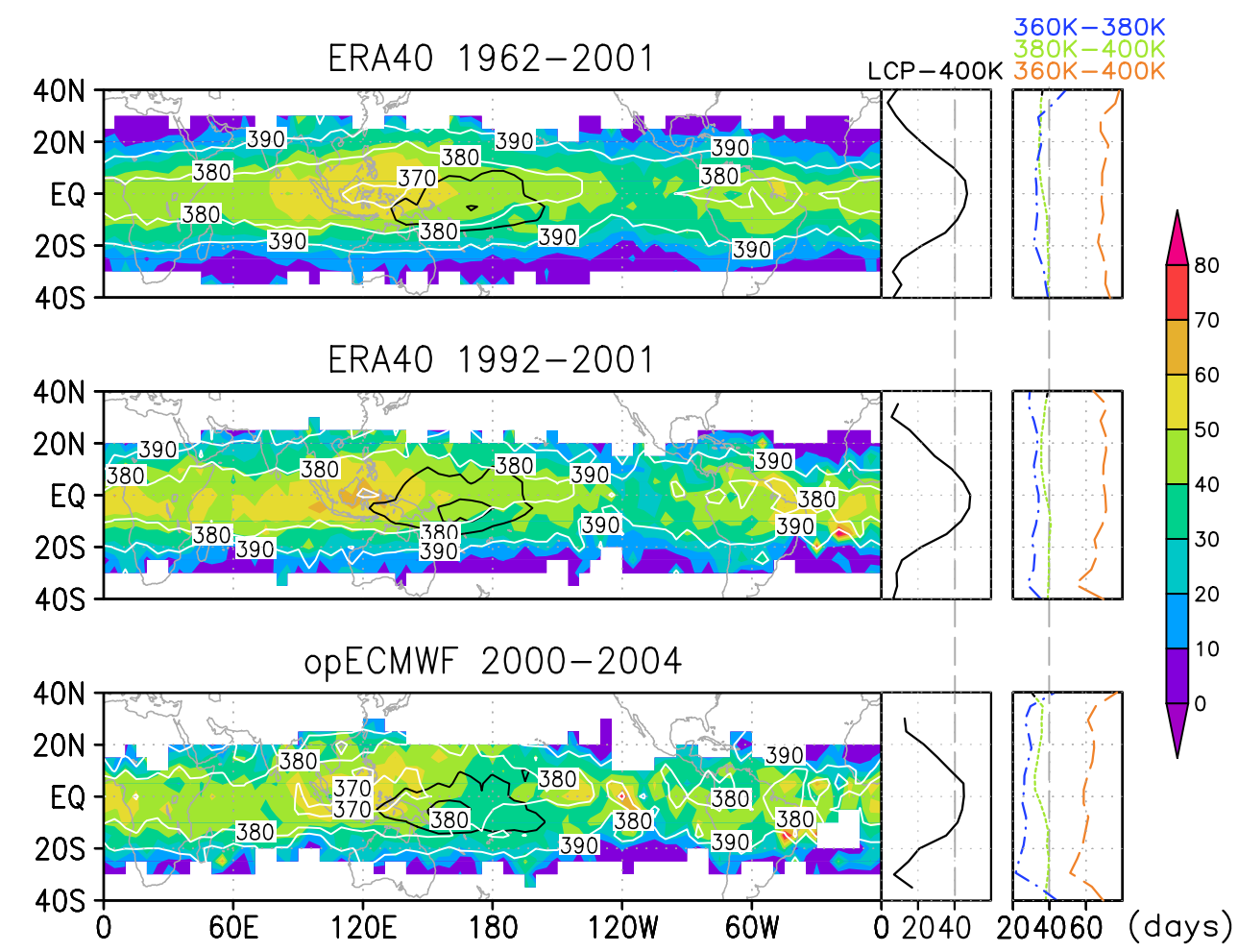

Fig. 1. DJF long-term climatology; Left: $\tau_{\mathrm{LCP}-400 \mathrm{~K}}$ [days] (color shading), $\Theta[\mathrm{K}]$ and density of LCPs (white and black contours); Right: Zonal mean $\tau$ [days] for LCP-400 K (black line), $380 \mathrm{~K}-400 \mathrm{~K}$ (green line), $360 \mathrm{~K}-380 \mathrm{~K}$ (blue line) and $360 \mathrm{~K}-400 \mathrm{~K}$ (orange line). Top panel: 1962/1963-2001/2002 ERA40 data; middle panel: 1992/1993-2001/2002 ERA40 data; lower panel: opECMWF data from 2000/2001-2004/2005. Contour intervals for the trajectory density are 0.005 and 0.01 per $5^{\circ} \times 5^{\circ}$ grid.

the Equator during the 1962-2001 DJF period. According to this, $\tilde{Q}_{380 \mathrm{~K}-400 \mathrm{~K}}$ has its maximum upwelling $(0.65 \mathrm{~K} /$ day $)$ north of the Equator (not shown), probably influenced by the enhanced eddy driven circulation towards the active winter stratosphere (K08). This meridional pattern vanishes for

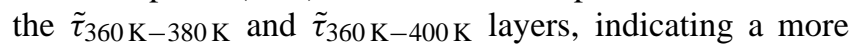
pronounced tropospheric influence for this part of the TTL.

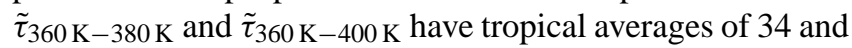

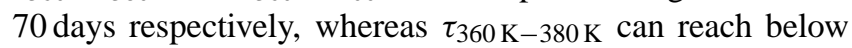
25 days over the tropical Pacific.

The other two time periods (Fig. 1, middle and lower panel) reflect the results shown previously by (K08). Even though the DJF period 1991-2001 was colder than 19622001 (Fig. 3 in K08), less tropical upwelling occurred, which is in agreement with weaker wave driving observed during the cold NH winters in the early to mid 1990s (Pawson and Naujokat, 1999). This leads to a longer residence time over parts of the Indonesian islands ( $>60$ days), although the LCP theta layer lies higher compared to 1962-2001, reflecting the complex influence of LCP temperature, height and $Q$ on $\tau$. The lower panel of Fig. 1 illustrates the 5year mean of opECMWF data during the early 2000s, which has a smaller area of maximum $\tau_{\mathrm{LCP}-400 \mathrm{~K}}$ of 50 days over the maritime continent, although the LCP theta layer has a minimum $\Theta$ with largest extension. Inspecting $\tilde{Q}_{\mathrm{LCP}-400 \mathrm{~K}}$ (not shown) reveals that the strongest diabatic heating of $0.7 \mathrm{~K} /$ day occurs within this time period, maximizing just north of the Equator, which is also present in $\tilde{Q}_{380 \mathrm{~K}-400 \mathrm{~K}}$. This higher $\tilde{Q}$ leads to a shorter $\tilde{\tau}_{380 \mathrm{~K}-400 \mathrm{~K}}$ in the same region (Fig. 1, right side). Tropical averaging $\tau(\hat{\tau})$ for the 380-400 K layer gives 37 days for 1962-2001, increasing to 38 days for 1992-2001 and decreasing to 36 days for the 2000-2004 DJF period. However, changes of $\hat{\tau}_{360 \mathrm{~K}-380 \mathrm{~K}}$ and $\hat{\tau}_{360 \mathrm{~K}-400 \mathrm{~K}}$ for the different time periods are not coherent with $\hat{\tau}_{380 \mathrm{~K}-400 \mathrm{~K}}$, indicating the presence of another influence possibly from the troposphere. The tropical averages

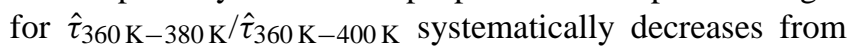
$36 / 69$ days for $1962-2001$, to $32 / 69$ days for $1992-2001$ and 26/60 days for the 2000-2004 DJF period. The maximum density of LCP trajectories, located over the warm pool (K08 and Fig. 1), coincides with regions of $\tau_{360 \mathrm{~K}-380 \mathrm{~K}}<25$ days (not shown here). This indicates, that a large amount of air parcels reaches $380 \mathrm{~K}$ (stratospheric air), which is approximately the height of the LCP (Fig. 1), within the TTL in less than 25 days during $\mathrm{NH}$ winter. 

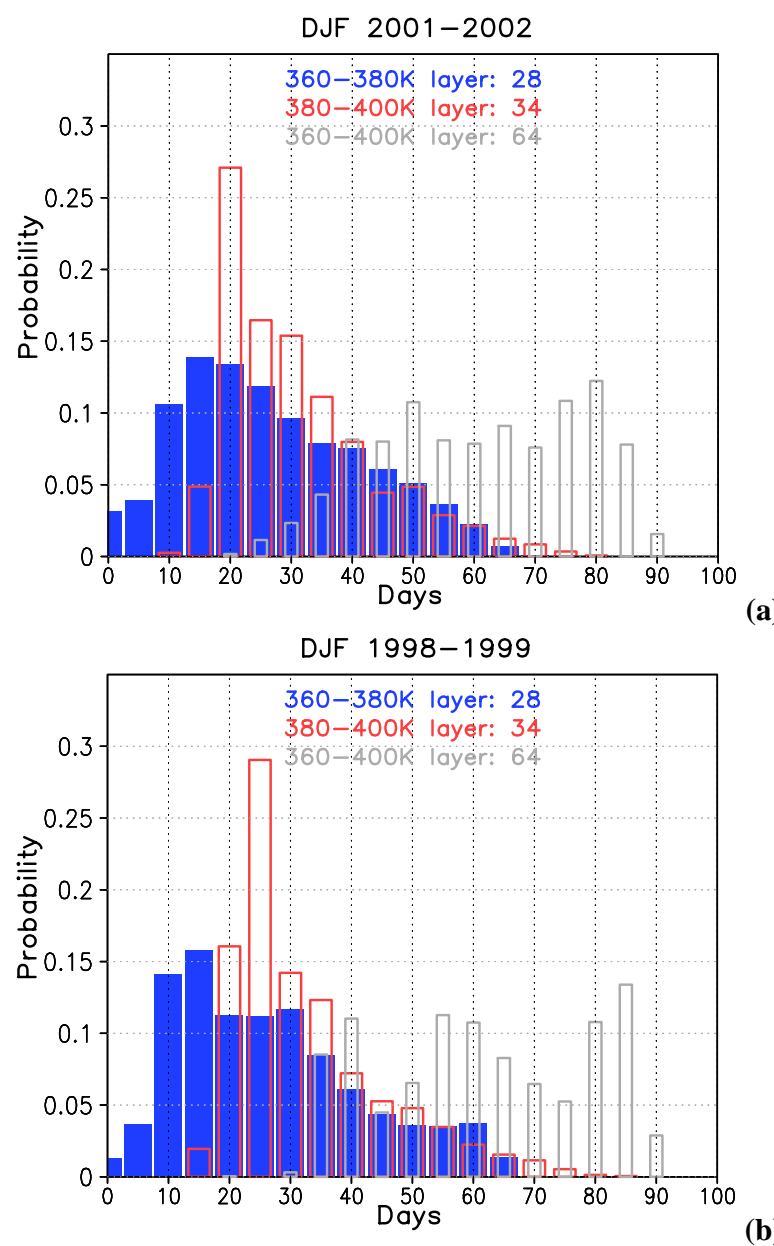

(b)

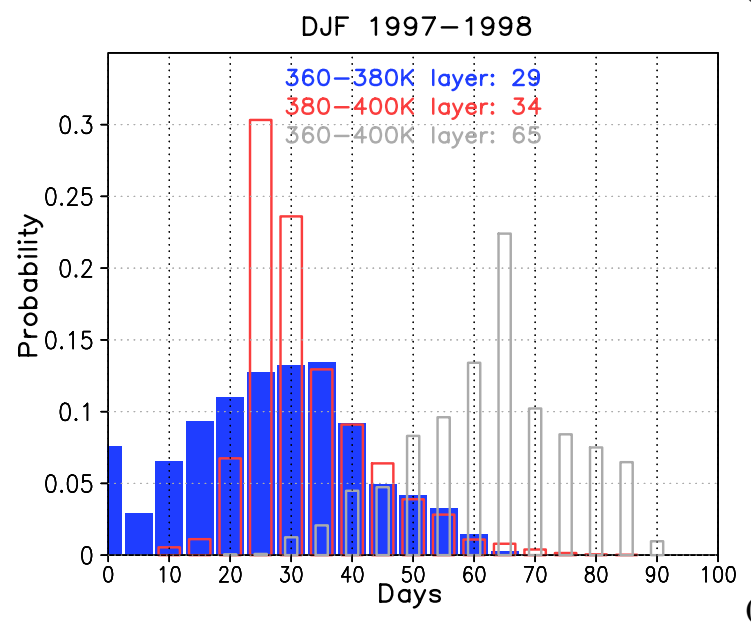

(c)

Fig. 2. PDF of $\tau_{380 \mathrm{~K}-400 \mathrm{~K}}$ (red bars), $\tau_{360 \mathrm{~K}-380 \mathrm{~K}}$ (blue filled bars) and $\tau_{360 \mathrm{~K}}-400 \mathrm{~K}$ (grey bars) for DJF trajectories of: (a) ENSO neutral winter 2001-2002, (b) La Niña winter 1998-1999 and (c) El Niño winter 1997-1998; given in [days] taking 5 day centered theta bins into account. The coloured numbers give the corresponding winter average of $\tau$.

\subsection{Statistical distribution of residence time: a case study}

For the rest of this study we concentrate on fixed theta layers, avoiding the dependence of $\tau_{\mathrm{LCP}}$ on the LCP height. For a better understanding of the spatial and temporal variability, Fig. 2 presents the probability density function (PDF) of $\tau$ for given theta layers, concentrating on years with different ENSO phases. ENSO shows a clear spatial variation of LCP temperature and density distribution (Bonazzola and Haynes, 2004; Fueglistaler and Haynes, 2005; K08). The PDF residence time is sampled within 5-day bins centered at $0,5,10, \ldots, 90$ days. Thus, averaging the PDF residence time for one specific winter from Fig. 2 can give slightly different values compared to the winter averages derived from the synoptic maps (Fig. 1, see Sect. 2). $\tau_{380 \mathrm{~K}-400 \mathrm{~K}}$ for the ENSO neutral year 2001-2002 (red bars in Fig. 2a) displays a maximum peak of $0.27(27 \%)$ probability at 20 days with a positive skew towards longer $\tau$ reaching up to 75 days (0.01 probability). The temporal average of $\tau$ ( $\bar{\tau}$, calculated from the PDF) has a duration time of 34 days for air parcels travelling from $380 \mathrm{~K}$ to $400 \mathrm{~K}$. The theta layer between $360 \mathrm{~K}$ to $380 \mathrm{~K}$ (blue filled bars) displays a maximum of 15 days ( 0.14 probability) with a shorter right tail reach-

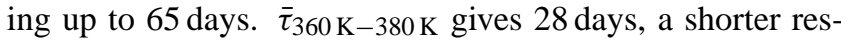
idence time than for the TTL layer above. Note that the average $\tau$ derived from the PDF in Fig. 2 is the $\tau$ derived from the Lagrangian histories of the air masses. This differs from $\tau$ that could be determined from averaging ascent rates at grid points in an Eulerian way, which would not reflect the real $\tau$ for the traveling air masses. It also differs slightly from values that would be derived from averaging over all geographical boxes shown in Fig. 1, because these Eulerian boxes do not contribute with even weight to the fully Lagrangian average shown here. The grey bars show $\tau$ between $360 \mathrm{~K}$ and $400 \mathrm{~K}$ theta layers, having an almost uniform distribution, indicating the influence of independent tropospheric and stratospheric processes on the vertical ve-

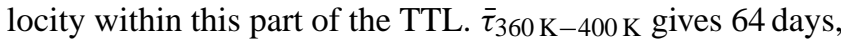
varying from 20 up to 90 days. Fig. 2 b displays the La Niña year 1998-1999. As might be expected, the overall shape is similar to the neutral ENSO year 2001-2002, with a rightskewed distribution. The maximum $\tau_{380 \mathrm{~K}-400 \mathrm{~K}}$ is shifted towards a longer residence time of 25 days, with the highest probability of 0.29 , whereas $\tau 360 \mathrm{~K}-380 \mathrm{~K}$ is unevenly distributed and shifted towards shorter residence times of 10 to 15 days. Although the shape of the PDFs are slightly different to the ENSO neutral year 2001-2002, there is no change in $\bar{\tau}$. In contrast, the strong El Niño winter 1997-1998 (Fig. 2c) shows the clearest difference in the PDF distribution compared to the previous cases, with a symmetric distribu-

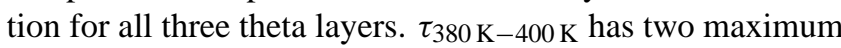
bars at 25 and 30 days ( 0.3 and 0.23 probability), $\tau_{360} \mathrm{~K}-380 \mathrm{~K}$

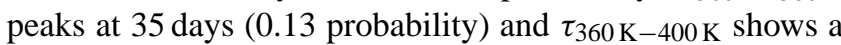
distinct maximum at 65 days with a high probability of 0.22 . 
Although the PDFs have changed considerably compared to Fig. 2a and b, with a shift of the maxima to the right, only a slight increase of $\bar{\tau}$ is calculated. For this El Niño case, the maxima of $\tau_{360 \mathrm{~K}-380 \mathrm{~K}}$ and $\tau_{380 \mathrm{~K}-400 \mathrm{~K}}$ approximately sum up to the maximum of $\tau_{360 \mathrm{~K}-400 \mathrm{~K}}$, indicating that both layers have an influence on 360-400 K.

Concluding, during ENSO neutral and La Niña cases we find a right-skewed distribution for $\tau_{360 \mathrm{~K}-380 \mathrm{~K} \text { and }}$

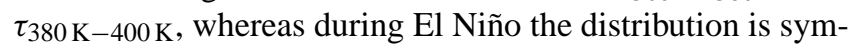
metric. A positive skew usually leads to a higher mean of the PDF due to the long right tail. Taking $380 \mathrm{~K}$ theta as the mean upper TTL layer, we can calculate the percentage of air parcels passing the TTL in less than 25 days. Almost $60 \%$ of the air needs less than 25 days travelling from $360 \mathrm{~K}$ to $380 \mathrm{~K}$ during ENSO neutral and La Niña years, whereas it accounts for less (48\%) during El Niño years.

\subsection{Interannual variability of residence time}

The interannual variability of tropically averaged $\hat{\tau}$ is displayed in Fig. 3 for three different theta layers, covering the ERA40 and opECMWF time period from 1962-1963 until

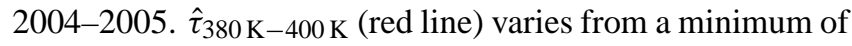
31 days during 1986-1987 up to 46 days during 1992-1993, displaying a higher variability than given by different ENSO events (Sect. 3.2). The average residence time is $38 \pm 5.1$ days ( $2 \sigma$ standard deviation). The time series of $\tau_{380 \mathrm{~K}-400 \mathrm{~K}}$ is highly correlated with $\tau_{\mathrm{LCP}-400 \mathrm{~K}}$ (not shown here). The corresponding $\hat{Q}_{380 \mathrm{~K}-400 \mathrm{~K}}$ varies from $0.48 \mathrm{~K} /$ day during $1992-1993$ to $0.72 \mathrm{~K} /$ day during $1986-1987$ with an average of $0.59 \mathrm{~K} /$ days (not shown here). $\hat{\tau}_{360 \mathrm{~K}-380 \mathrm{~K}}$ (blue line) varies from a minimum of 23 days during $1982-1983$ up to 41 days during 1974-1975, with an average residence time of $34 \pm 7.3$ days, shorter than for the $380-400 \mathrm{~K}$ layer. There seems to be a negative trend for NH winter from 1962-1963 to 2001-2002, using the ERA40 time series. Inspecting $\hat{\tau}$ for the $360 \mathrm{~K}$ to $400 \mathrm{~K}$ theta layer (grey line), which is ap-

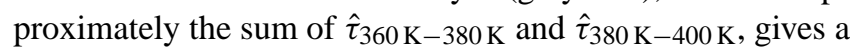
residence time with an average of $70 \pm 7.6$ days. Correspondingly, a negative trend also exists for the $360 \mathrm{~K}$ to $400 \mathrm{~K}$ layer, but not for the $380 \mathrm{~K}$ to $400 \mathrm{~K}$ layer. According to this, the time series of $\hat{\tau}_{360 \mathrm{~K}-380 \mathrm{~K}}$ has no correlation with $\hat{\tau}_{380 \mathrm{~K}-400 \mathrm{~K}}(r=-0.14)$, underlining the different characteristics of these two TTL layers (see Sect. 3.2). There is strong interannual variability, varying for $\hat{\tau}_{360 \mathrm{~K}-400 \mathrm{~K}}$ from maximum 76 days during 1973-1975 to minimum 60 days during 1982-1983. As expected, $\hat{Q}_{360 \mathrm{~K}-400 \mathrm{~K}}$ shows an increase from 1962-1963 to 2001-2002 and a high interannual variability, varying from a minimum of $0.54 \mathrm{~K} /$ days during 1973-1974 up to $0.73 \mathrm{~K} /$ day maximum during 1982 1983 (not shown here). This temporal behaviour of $\hat{\tau}$ and $\hat{Q}$ derived for the $360 \mathrm{~K}$ to $380 \mathrm{~K}$ theta layer seems to be connected with the reported trend of tropical tropopause height increase (Seidel and Randel, 2006), which is also visible by the increase of the LCP tropopause height over the

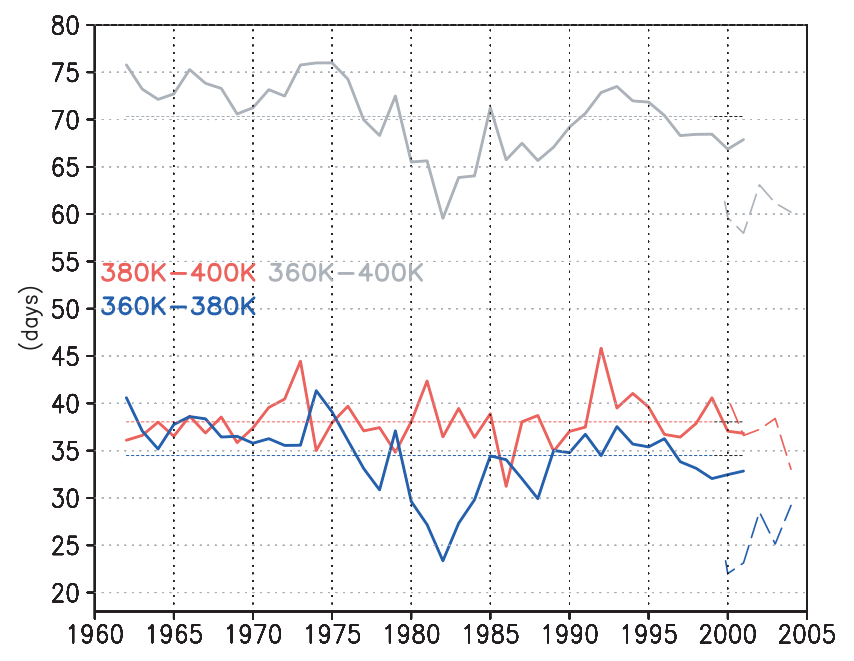

Fig. 3. Interannual variability of $\hat{\tau}_{380 \mathrm{~K}-400 \mathrm{~K}}$ (red line),

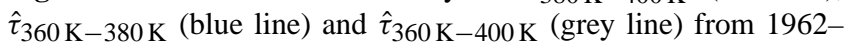
1963/2004-2005. $\hat{\tau}$ is calculated from Fig. 1 . The short dashed lines give the long-term mean of $\tau$. The solid/long dashed lines display ERA40/opECMWF data.

time periods shown in Fig. 1. An increase of the tropical tropopause height within the $360 \mathrm{~K}$ to $380 \mathrm{~K}$ layer could be connected with a stronger tropospherically induced upwelling, and hence with a shorter residence time within this TTL layer. The distinct differences in $\hat{\tau}$ time series lead to the conclusion that the $380 \mathrm{~K}$ to $400 \mathrm{~K}$ region might be dominated by stratospheric processes (the eddy-driven residual circulation), whereas the $360 \mathrm{~K}$ to $380 \mathrm{~K}$ region reveals influences of tropospheric processes, which are accompanied by a positive trend of the tropical tropopause height. The question of whether a trend in $\tau$ and $Q$ exists, or if it is a bias due to systematic changes in the ERA40 data assimilation procedure (Simmons et al., 2005), is discussed in more detail by K08. There is no distinct signal of ENSO events or volcanic eruptions visible in the time series (Fig. 3), although these natural forcing events showed the largest impact on the LCP temperature and density distribution (K08). Thus, there have to be other or overlapping processes influencing the strong interannual variability of residence time in the TTL, which will be analysed in more detail in the next section.

\subsection{Correlations with the Eliassen Palm-Flux}

Tropical upwelling in the stratosphere is mainly driven by extratropical and equatorial waves (Randel et al., 2008). To address the influence of extratropical and subtropical wave driving on the residence time in the TTL in more detail, we assess the correlation between $\tau$ during $\mathrm{NH}$ winter and the Eliassen Palm (EP)-Flux averaged for NH and SH winter using the ERA40 data. We calculate the correlations for pressure levels varying between 300 and $0.1 \mathrm{hPa}$ for the EPFlux diagnostic and for theta levels varying between $360 \mathrm{~K}$ 

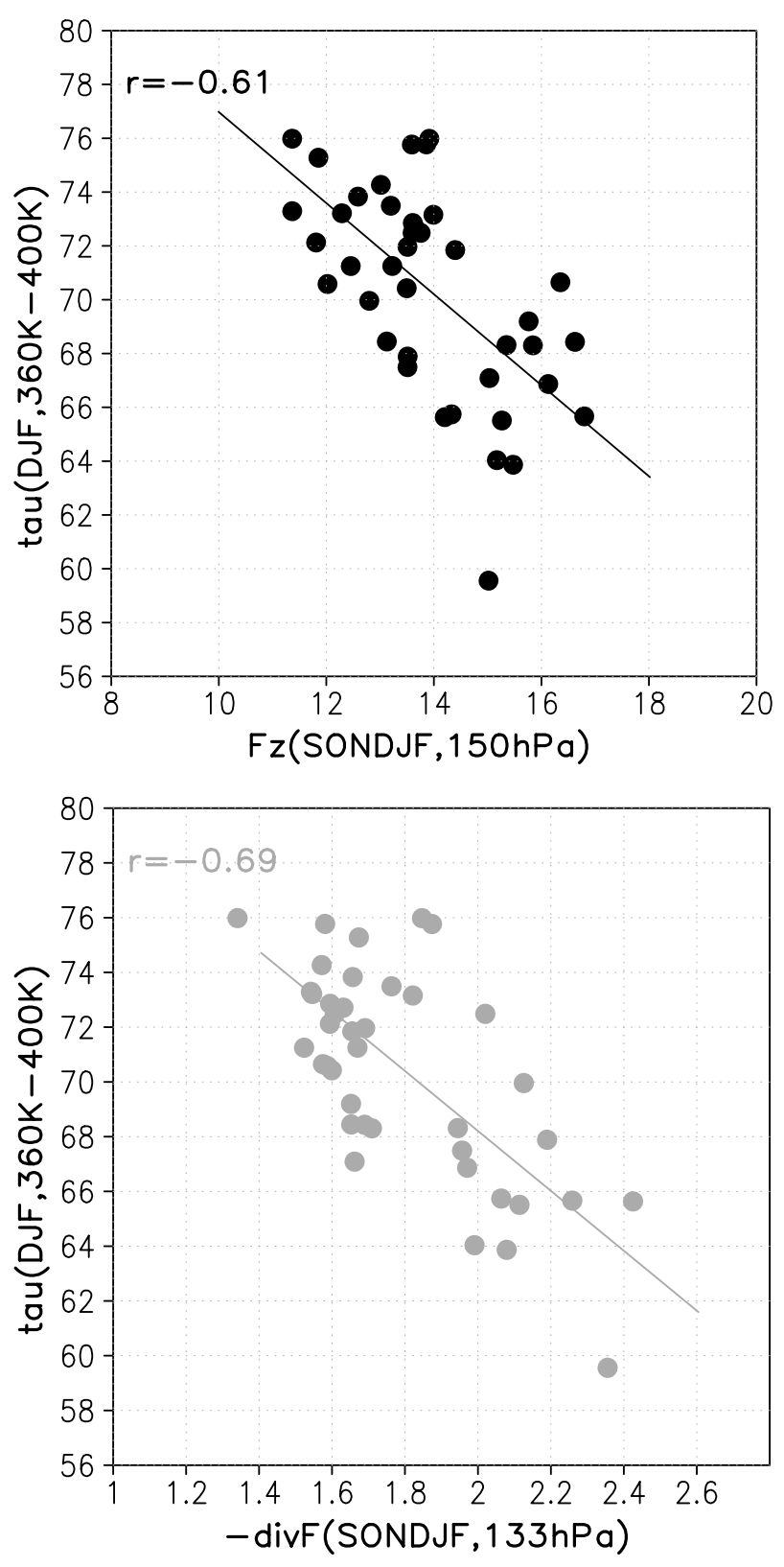

(b)

Fig. 4. Scatter plots and correlation coefficients between: (a) $F_{z}\left[10^{5} \mathrm{~kg} / \mathrm{s}^{2}\right]$ at $150 \mathrm{hPa}$ and $\hat{\tau}_{360 \mathrm{~K}}-400 \mathrm{~K}$ [days]; (b) $-\operatorname{div} F$

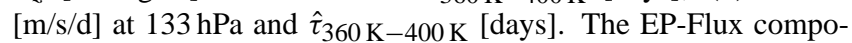
nents are averaged for: (a) SON $45-75^{\circ} \mathrm{S}$ and DJF $45-75^{\circ} \mathrm{N}$; (b) SON $10-20^{\circ} \mathrm{S}$ and DJF $10-20^{\circ} \mathrm{N}$; using ERA40 data from 1962 1963/2001-2002.

and $400 \mathrm{~K}$ for the $\tau$, but only maximum correlations are presented.

The maximum correlation was found between the vertical component of the extratropical EP-Flux $\left(F_{z}\right)$, averaged between $45^{\circ}$ and $75^{\circ} \mathrm{S} / \mathrm{N}$ for SON/DJF at $150 \mathrm{hPa}$, and the

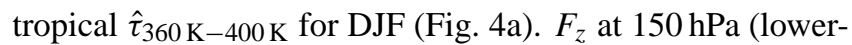
most stratosphere) gives the amount of extratropical upward propagating planetary waves reaching stratospheric levels. $F_{z}$ and $\hat{\tau}_{360 \mathrm{~K}-400 \mathrm{~K}}$ are anticorrelated with $r=-0.61$ at $99 \%$ significance. Intensified extratropical planetary wave propagation into the stratosphere generates enhanced extratropical wave driving, which is balanced by intensified forced diabatic ascent in the tropics, hence leading to a shorter residence time in the TTL. There is one clear outlier in the scatter diagram at $15 \cdot 10^{5} \mathrm{~kg} / \mathrm{s}^{2}$ and 60 days, which is the $\mathrm{NH}$ winter 1982-1983. This is the first winter, following the El Chichon eruption in April 1982. However, no such deviation is visible for the NH winters 1963-1964 and 19911992, following the major volcanic eruptions of Mt. Agung (March 1963) and Mt. Pinatubo (June 1991). During the early 1980s, the ERA40 assimilation has a cold bias of 1 to 2 K (e.g. Fueglistaler and Haynes, 2005), which could lead to a stronger $Q$, hence shorter $\tau$, impacting our analysis.

Figure $4 \mathrm{~b}$ reveals the maximum correlation between the subtropical wave driving $(\operatorname{div} F<0)$, averaged between $10^{\circ}$ and $20^{\circ} \mathrm{S} / \mathrm{N}$ for $\mathrm{SON} / \mathrm{DJF}$ at $133 \mathrm{hPa}$ and tropical

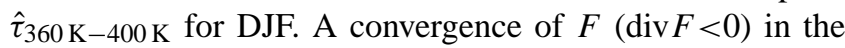
stratosphere leads to a deceleration of the westerly flow and thus to a strengthening of the residual circulation on the winter hemisphere side, the so called "wave driving" of the eddy driven residual circulation. We derive a strong anticorrelation of $r=-0.69$ (99\% significant) between the subtropical wave

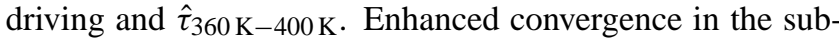
tropics leads to a shorter residence time between $360 \mathrm{~K}$ and $400 \mathrm{~K}$. For $\hat{\tau}_{360 \mathrm{~K}-380 \mathrm{~K}}$ the anticorrelation minimizes even to $r=-0.74$. Randel et al. (2008) found a strong convergence of the EP-Flux in the subtropical troposphere up to $100 \mathrm{hPa}$ during $\mathrm{NH}$ and $\mathrm{SH}$ winter season due to extratropical and equatorial wave forcing. They also showed that this EP-Flux convergence is in balance with upwelling across the tropical tropopause. In accordance with this, we find that enhanced extratropical and subtropical wave driving leads to shorter $\hat{\tau}$ (stronger $\hat{Q}$ ) for the TTL between the $360 \mathrm{~K}$ to $400 \mathrm{~K}$ theta layers.

\section{Discussion}

The results of this study are based on ECMWF data and have to be interpreted accordingly. Data inhomogeneities are reported for ERA40 and opECMWF assimilations, which are addressed by several studies (Simmons et al., 2005; Uppala et al., 2005; Fueglistaler and Haynes, 2005; Krüger et al., 2008; Fueglistaler et al., 2009). Biases in the ECMWF input data e.g. temperature, ozone and cloud fields can affect our radiative heating rates: Lower temperatures and higher ozone concentrations in the tropical tropopause region lead to an increase of $Q$, hence decrease of $\tau$, in the TTL. In the beginning of the 1980s, a cold bias was reported for ERA40 tropical temperatures at $100 \mathrm{hPa}$ (Fueglistaler and Haynes, $2005)$, which probably caused the outlier of $\tau$ (a minimum) in Fig. 4. K08 calculated an increase of radiative heating 
in the TTL using the standard ECMWF ozone climatology compared with the assimilated ECMWF ozone. The cloud fields were used on the 60 hybrid coordinate model levels of ECMWF as meteorological input for our radiative transfer calculations. We found a surprisingly good representation of ECMWF cirrus clouds compared with lidar observations in the tropics (Krüger et al., 2005) and in mid-latitudes (Immler et al., 2008). Using our trajectory calculations with radiative heating rates, Immler et al. (2007) found a good correlation between cirrus simulations and lidar observations of tropical cirrus. Thus, we conclude that the radiative effects of cirrus clouds are included in our trajectory calculations.

However, latent heat and mixing (diffusive and turbulent heat transport) are not included in our offline calculated diabatic heating rate $Q$, which only includes the radiative terms. While this is a minor limitation in the radiatively controlled region above $\sim 380 \mathrm{~K}$, it adds uncertainties to our estimates in the $360 \mathrm{~K}-380 \mathrm{~K}$ region. Problems may arise from latent heat release from cirrus cloud formation and vigorous local vertical motion driven by latent heat release in convective systems that occasionally reach levels above $360 \mathrm{~K}$. Fueglistaler et al. (2009) calculated for the latent heat and mixing (the missing term (residual) for the diabatic heating) up to $0.1 \mathrm{~K} /$ day between $360 \mathrm{~K}-370 \mathrm{~K}$, becoming zero or slightly negative above $370 \mathrm{~K}$ for the 2000 annual mean period. Ploeger et al. (2009) derives for the same residual term a $\sim 10 \%$ shorter/longer $\tau$ for the $340 \mathrm{~K}-400 \mathrm{~K} / 370 \mathrm{~K}-$ $400 \mathrm{~K}$ layers during DJF 2001-2002. Taking into account the missing residual term, we might derive a slightly shorter residence time for $360 \mathrm{~K}-380 \mathrm{~K}$ and $360 \mathrm{~K}-400 \mathrm{~K}$ and a slightly longer residence time for $380 \mathrm{~K}-400 \mathrm{~K}$. As no direct measurements of diabatic heating rates are available these are assumptions and can only be used as a possible guidance for the uncertainties of the TTL residence time. Using aircraft measurements of longer lived trace gases, Andrews et al. (1999) derives a transit time of 55 days for the $390 \mathrm{~K}$ to $420 \mathrm{~K}$ layers during February 1994-1997, which is close to our derived long term mean of 38 days for the $380 \mathrm{~K}$ to $400 \mathrm{~K}$ layers.

Given the above mentioned limitations for the lower TTL calculations, the results should be interpreted accordingly. Nevertheless, we find distinct differences in our study between the three considered theta layers, leading to the conclusion that the $380 \mathrm{~K}$ to $400 \mathrm{~K}$ layers are influenced by stratospheric processes, whereas the $360 \mathrm{~K}$ to $380 \mathrm{~K}$ layers show some tropospheric influences. The residence time including the lower part of the TTL $\left(\hat{\tau}_{360 \mathrm{~K}}-380 \mathrm{~K}, \hat{\tau}_{360 \mathrm{~K}-400 \mathrm{~K}}\right)$ indicates a negative trend towards shorter residence times, which corresponds with the previously observed positive trend in the tropical tropopause height (Seidel and Randel, 2006). In contrast to this, the residence time for the $380 \mathrm{~K}$ to $400 \mathrm{~K}$ theta layers shows an increase during $\mathrm{NH}$ winters of the 1990s (ERA40), the period of weaker extratropical wave driving, reducing in the early 2000s (opECMWF). These trends might be influenced by the above mentioned uncertainties of the ECMWF assimilations. However, the main focus of our study is the interannual variability of residence time and we do not believe that the data uncertainties have a large impact on the strength of the variability.

\section{Conclusions}

Concerning the interannual and spatial variability of residence time, the following new results are derived for $\mathrm{NH}$ winters from 1962-1963 to 2004-2005:

1. The residence time between the LCP and $400 \mathrm{~K}$ depends on the height of the LCP, which varies over time and location. In that respect a lower LCP tropopause corresponds with a longer residence time for the LCP and $400 \mathrm{~K}$ layer, but with a shorter residence time for the $360 \mathrm{~K}$ to LCP $(\sim 380 \mathrm{~K})$ layer. This leads to the signature that $\tau_{\mathrm{LCP}-400 \mathrm{~K}}$ displays a spatially varying pattern, maximizing over the maritime continent, with the longest residence time found for the 1990s.

2. Zonally averaging the residence time for fixed theta layers gives a different meridional structure than that seen for the LCP to $400 \mathrm{~K}$ layers. For $380 \mathrm{~K}$ to $400 \mathrm{~K}$, a shorter residence time (enhanced diabatic ascent) is found north of the Equator towards the winter hemisphere, which is probably due to the influence of enhanced extratropical wave driving. However, the residence time for the $360 \mathrm{~K}$ to $380 \mathrm{~K}$ and $360 \mathrm{~K}$ to $400 \mathrm{~K}$ layers has no defined meridional structure.

3. Averaging the residence time for the ERA40 DJF period from 1962-1963 to 2001-2002 gives a mean and $2 \sigma$ standard deviation of $34 \pm 7.3$ days for the $360 \mathrm{~K}$ to $380 \mathrm{~K}, 38 \pm 5.1$ days for the $380 \mathrm{~K}$ to $400 \mathrm{~K}$ and $70 \pm 7.6$ days for the $360 \mathrm{~K}$ to $400 \mathrm{~K}$ theta layers. The variance of tropically averaged $\tau$ amounts to $\pm 40 \%$, maximizing for the lower TTL between $360 \mathrm{~K}$ and $380 \mathrm{~K}$.

4. Correlation analysis with the EP-Flux suggests that the high internannual variability of $\tau$ is caused by upward propagating extratropical planetary waves and by enhanced convergence in the subtropics in the lowermost stratosphere, during SH spring (SON) and NH (DJF) winter season. Enhanced extratropical and subtropical wave driving leads to a shorter residence time. Randel et al. (2008) first showed that this wave driving is in balance with upwelling across the tropical tropopause using an Eulerian approach and different vertical velocity fields.

5. Statistical analysing $\tau$ for different ENSO cases reveals a right-skewed distribution for ENSO neutral and La Niña and a symmetric distribution for El Niño years. Within 25 days $\sim 60 \%$ of air parcels travel through the 
$360 \mathrm{~K}$ to $380 \mathrm{~K}$ layers during the ENSO neutral winter 2001-2002 and the La Niña winter 1998-1999, whereas less air parcels $(48 \%)$ reach $380 \mathrm{~K}$ during $\mathrm{El}$ Niño (1997-1998).

6. Of relevance for VSLS transport in the TTL is the residence time between the $360-380 \mathrm{~K}$ theta layers, which has a minimum of less than 20 days over the tropical Western Pacific during the early 2000s period (not shown) coinciding with the maximum density of trajectories crossing the LCP, hence reaching the stratosphere.

Our study illustrates the large spatial and interannual variability of residence time during NH winter season, which has to be considered in future TTL transport studies. Generally a decrease of residence time in the TTL leads to a faster supply and different ratios of VSL primary and secondary source gases transported into the stratosphere. In that respect a negative trend in residence time in a future climate could have a significant influence on the stratospheric ozone layer as the chlorine loading is expected to relax to pre-industrial levels.

Acknowledgements. We would like to thank the ECMWF for providing the meteorological analyses and the technical data support. The authors thank two anonymous reviewers and the editor Rob MacKenzie for their useful commends, which helped to improve this manuscript. This study was partly funded by the European Union's SCOUT-O 3 (GOCE-CT-2004-505390) and SHIVA (SHIVA-226224-FP7-ENV-2008-1) projects.

Edited by: R. MacKenzie

\section{References}

Andrews, A., Boering, K., Daube, B., Wofsy, S., Hintsa, E., Weinstock, E., and Bui, T.: Empirical age spectra for the lower tropical stratosphere from in situ observationso of $\mathrm{CO}_{2}$ : Implications for stratospheric transport, J. Geophys. Res., 104, 26581-26595, 1999.

Bonazzola, M. and Haynes, P.: A trajectory-based study of the tropical tropopause region, J. Geophys. Res., 109, D20112, doi: 10.1029/2003JD004356, 2004.

Dunkerton, T.: On the mean meridional mass motions of the stratosphere and mesosphere, J. Atmos. Sci., 35, 2325-2333, 1978.

Fueglistaler, S. and Haynes, P.: Control of interannual and longerterm variability of stratospheric water vapor, J. Geophys. Res., 110, D24108, doi:10.1029/2005JD006019, 2005.

Fueglistaler, S., Wernli, H., and Peter, T.: Stratospheric water vapor predicted from the Lagrangian temperature history of air entering the stratosphere in the tropics: J. Geophys. Res., 110, D03108, doi:10.1029/2003JD004069, 2004.

Fueglistaler, S., Legras, B., Beljaars, A., Morcrette, J. J., Simmons, A., Tompkins, A. M., and Uppala, S.: The diabatic heat budget of the upper troposphere and lower/mid stratosphere in ECMWF reanalysis, Q. J. R. Meteorol. Soc., 135(638), 21-37, 2009.

Haynes, P., Marks, C., McIntyre, M., Shepherd, T., and Shine, K.: On the "Downward Control" of extratropical diabatic circulations by eddy-induced zonal mean forces, J. Atmos. Sci., 49, 651-679, 1991.
Holton, J. and Gettelman, A.: Horizontal transport and the dehydration of the stratosphere, Geophys. Res. Lett., 28, 2799-2802, 2001.

Immler, F., Krüger, K., Tegtmeier, S., Fujiwara, M., Fortuin, P., Verver, Gé, and Schrems, O.: Cirrus clouds, humidity, and dehydration in the tropical tropopause layer observed at Paramaribo, Suriname $\left(5.8^{\circ}\right.$ N, 55.2 ${ }^{\circ}$ W), J. Geophys. Res., 112, D03209, doi: 10.1029/2006JD007440, 2007.

Immler, F., Treffeisen, R., Engelbart, D., Krüger, K., and Schrems, O.: Cirrus, contrails, and ice supersaturated regions in high pressure systems at northern mid latitudes, Atmos. Chem. Phys., 8, 1689-1699, 2008, http://www.atmos-chem-phys.net/8/1689/2008/.

Kremser, S., Rex, M., Langematz, U., Dameris, M., and Wohltmann, I.: Validation of water vapour transport in the tropical tropopause region in coupled Chemistry Climate Models, Atmos. Chem. Phys., 9, 2679-2694, 2009, http://www.atmos-chem-phys.net/9/2679/2009/.

Krüger, K., Tegtmeier, S., Schöllhammer, K., Wohltmann, I., and Rex, M.: Transport through the tropical UTLS into the Extratropics, oral presentation at SCOUT-O3 annual meeting, Zuerich, March 8, 2005.

Krüger, K., Tegtmeier, S., and Rex, M.: Long-term climatology of air mass transport through the Tropical Tropopause Layer (TTL) during NH winter, Atmos. Chem. Phys., 8, 813-823, 2008, http://www.atmos-chem-phys.net/8/813/2008/.

Marcy, T. P., Popp, P. J., Gao, R. S., et al.: Measurements of trace gases in the tropical tropopause layer, Atmos. Environ., 41, 7253-7261, 2007.

Newell, R., and S. Gould-Stewart, A stratospheric fountain?:=, J. Atmos, Sci., 38, 2789-2796, 1981.

Park, S., Jiménez, R., Daube, B. C., Pfister, L., Conway, T. J., Gottlieb, E. W., Chow, V. Y., Curran, D. J., Matross, D. M., Bright, A., Atlas, E. L., Bui, T. P., Gao, R.-S., Twohy, C. H., and Wofsy, S. C.: The $\mathrm{CO}_{2}$ tracer clock for the Tropical Tropopause Layer, Atmos. Chem. Phys., 7, 3989-4000, 2007, http://www.atmos-chem-phys.net/7/3989/2007/.

Pawson, S. and Naujokat, B.: The cold winters of the middle 1990s in the northern lower stratosphere, J. Geophys. Res., 104, 14209$14222,1999$.

Plöger, F., Konopka, P., Günther, G., Grooß, J.-U., Müller, R.: Impact of the vertical velocity scheme on modeling transport in the tropical tropopause layer, J. Geophys. Res., in press, 2009.

Quack, B. and Wallace, D.: Air-sea flux of bromoform: Controls, rates, and implications, Global Biogeochem. Cy., 17, 1023, doi: 10.1029/2002GB001890, 2003.

Randel, W., Garcia, R., and Wu, F.: Dynamical Balances and Tropical Stratospheric Upwelling, J. Atmos. Sci., 65, 3584-3595, 2008.

Seidel, D. and Randel, W.: Variability and trends in the global tropopause estimated from radiosonde data, J. Geophys. Res., 111, D21101, doi:10.1029/2006JD007363, 2006.

Simmons, A., Hortal, M., Kelly, G., McNally, A., Untch, A., and Uppala, S.: ECMWF Analyses and Forecasts of Stratospheric Winter Polar Vortex Breakup: September 2002 in the Southern Hemisphere and Related Events, J. Atmos. Sci., 62(3), 668-689, 2005.

Tegtmeier, S., Rex, M., Krüger, K., Wohltmann, I., and Schoellhammer, K.: Variations of the residual circulation in the 
northern hemispheric winter, J. Geophys. Res., 113, D16109, doi:10.1029/2007JD009518, 2008.

Uppala, S., Kållberg, P. W., Simmons, A. J., et al.: The ERA-40 Reanalysis, Q. J. Roy. Meteor. Soc., 131(612), 2961-3012, 2005.

Wohltmann, I. and Rex, M.: Improvement of vertical and residual velocities in pressure or hybrid sigma-pressure coordinates in analysis data in the stratosphere, Atmos. Chem. Phys., 8, 265272, 2008,

http://www.atmos-chem-phys.net/8/265/2008/.
World Meteorological Organization: Scientific Assessment of Ozone Depletion: 2006, WMO Global Ozone Research and Monitoring Project, Report No. 50, 2007. 